\title{
The practice of building an information system for managing the operation of an industrial facility
}

\author{
Pavel Chelyshkov* and Kirill Aralkin \\ Moscow State University of Civil Engineering, Yaroslavskoe shosse, 26, Moscow, 129337, Russia
}

\begin{abstract}
This work is of interest to engineers engaged in the information modeling, management and operation of the building.

The subject of the study is the software product EcoDomus, where a study was conducted on the implementation and management of industrial buildings.

The purpose of the work is to consider the information management system using information modeling technologies, the advantages and disadvantages of software for managing building information systems, problems and opportunities for implementation.

We used methods for analyzing the literature and technical documentation, analyzing the use of the information modeling method, analyzing the monitored parameters of the software, project structuring method, analyzing graphical models.

Studies have been conducted on the implementation and management of an industrial facility. Conclusions have been made about the relevance of the use of these technologies for the management of the facility, the shortcomings of these technologies, as well as solutions for implementation.
\end{abstract}

\section{Introduction}

At the moment, each organization, before proceeding with the implementation of the next facility, is engaged in project planning, makes every step of the enterprise in accordance with a clearly defined plan, professional information management of the systems is very relevant and practically important issue in modern working conditions of enterprises in any field.

In the great majority of cases, the research and development of modern information management systems are carried out within the framework of different approaches based on mathematical models and processes within them [1]. If new information and control systems are created, the structure of their mathematical models is the purpose of research directed at achieving pre-set goals. First of all, the formulation of these goals is based on the formation of the mathematical description of the system, and it must have a

\footnotetext{
* Corresponding author: chelyshkovpd@mgsu.ru
} 
predetermined functionality, endowed with clearly defined properties and features that characterize a particular system and its assigned information processes [5].

During the last decade a new approach developped to the construction, equipping, maintenance and repair of the building (to the management of the object's life cycle) - BIM (Building Information Modeling or Building Information Model), which undoubtedly influenced the sector of building management and control. the facility in general, Facility Management is a direction that combines the organization and coordination of all building processes. This is a new and interesting topic that should definitely be analysed and actively implemented in Russia.

\section{Material and Methods}

BIM and FM technology have already demonstrated the possibility of achieving high speed, volume and quality of construction, as well as significant budget savings.

Currently is actively supported the software for FM maintenance. At the moment, the pool of computer programs is quite wide. Specialists working in the field of object management, often depend on the correct choice of software used. Since the choice of software affects the future work of the entire team of specialists, this choice should be made at an early stage and coordinated with all project participants.

After testing various software products for implementation of the information management system for industrial buildings, the EcoDomus software was chosen, as most adapted to Russian conditions,

In this work, is considered the full cycle of introducing an information system of an industrial building into a software product, the structures of each system are analyzed graphically, this gave an understanding of how to exploit this system, into which branches it is subdivided. Information modeling of the building and territory was carried out using the Autodesk Revit 2018 program, which gives possibility to structure all work processes as much as possible.

\section{Results}

This article describes the construction of such a system using a software product EcoDomus.

Work with EcoDomus product begins with the project manager and the main rates of the object, procurement schedules, reconstruction and endurance, all these factors help to organize the work of the enterprise as clearly as possible, in our case it is the object "Production base. Cold storage", figures 1 and 2. 


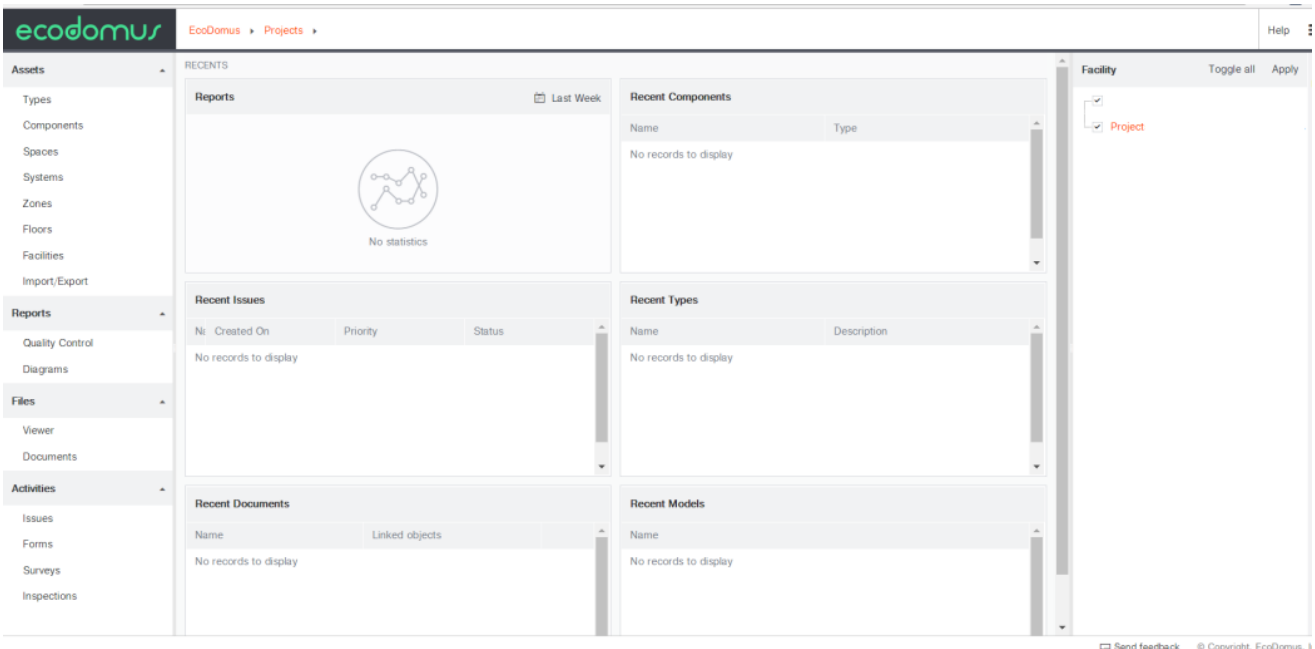

Fig. 1. General view of EcoDomus

You can also track the location of the selected object on the control. There is a function of indicating the nearest service, serving the company, and any other organizations.

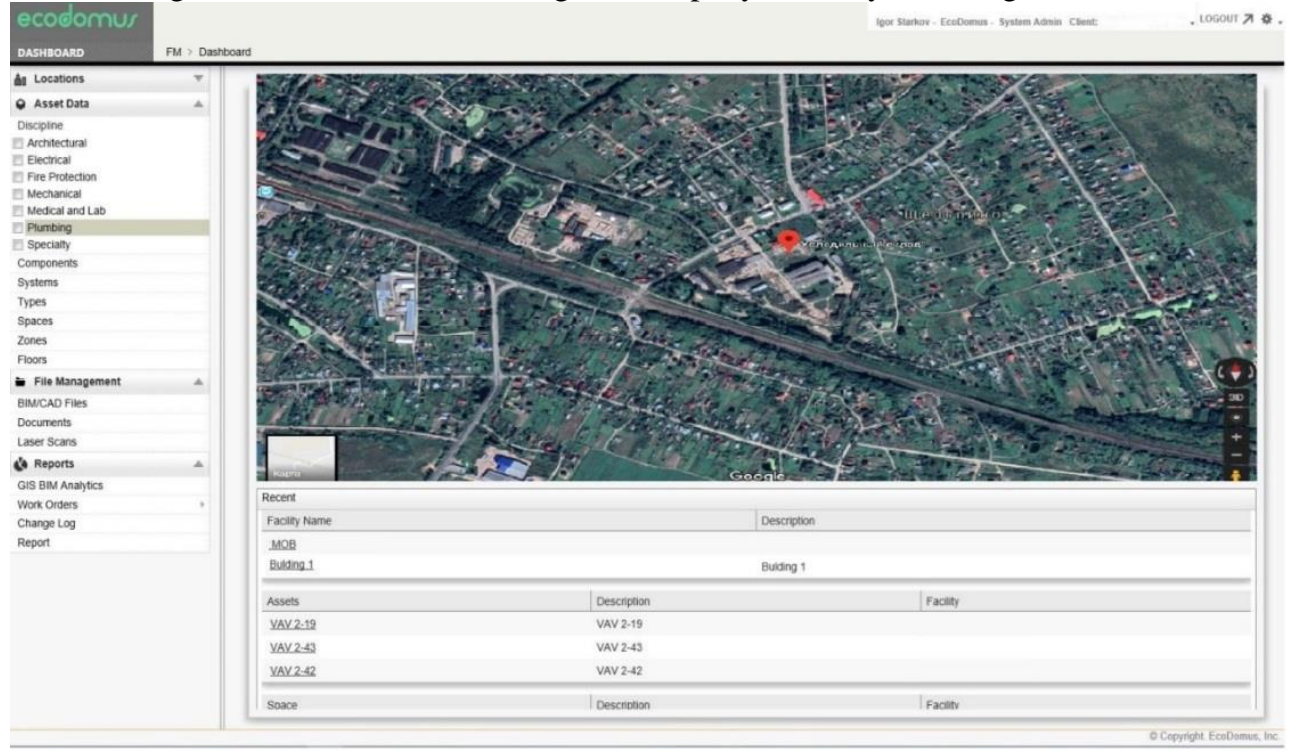

Fig. 2. Location of the object

All the participants of work organization of the enterprise are shown in the tab "Users", figures 3, each user is responsible for his/her own branch of the program, someone is in control of procurement, other is responsible for ensuring the smooth flow of cooling air in the refrigeration chamber. All of this helps to structure the work of the enterprise as much as possible. 


\section{ecodomus}

\begin{tabular}{|c|c|c|c|c|c|c|}
\hline Eoconomus, Users & & & & & & Help $\equiv$ \\
\hline Users & & & & & Search & \\
\hline Name , & T Organization & $T$ Trte & Phone & $\mathbf{T}$ & Emat & $T$ \\
\hline Aaron Morrison & PQL. Construction Semices & $P E$, LEED AP & 9073628198 & & ajmonisonepci.com & \\
\hline Aaron Schneider & REACH Consuthing & & $780-452.3435$ & & 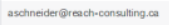 & \\
\hline Abtipt Chosh & Pinnacle intotech Technologes & Research \& Development Wng & 09430602222 & & madepinnaclecad.com & \\
\hline Adam Ungaran & Hotel Equipment Supply & & 000-000-0000 & & adamungaran@inotéequipmentsup & ppy.com \\
\hline Adeel Choudhiry & Siemens Canada Buildng Technologes & & $730-436 \cdot 1234$ & & adeel.choudhyesiemens.com & \\
\hline Adianna Schnoider & Adtanceed Souttions & Architectural Engineer & 8474201549 & & 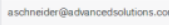 & \\
\hline Aemon Liang & Hevilet Packard & Design Engineed & & & teiliangęin3c.com & \\
\hline Nhmed Anemer & Seudi Arameo & Project Manage & $n ; a$ & & aahemerousce.ea & \\
\hline Almed Ataratrant & Seudi Aramco & Project Manages & $n ; 0$ & & asecanrigusc.eau & \\
\hline N Dean & sungerd & Bim mareper & 2159513617 & & al.deenesungerd.com & \\
\hline Aban Anaudinn & Saudi Aramco & Project Manager & $n / a$ & & airnddneuvsc.obu & \\
\hline Nejiancto Monterroso & Danta Architecture & Architect & & & amonter roso 0 dantac corp.com & \\
\hline Ner Saleh & Stantord Heain Care & вім & NA & & 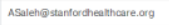 & \\
\hline Neexander Massour & symergy Systems & BIM & & & amaslovesyngys.00 & \\
\hline Alexandr ( $(m)$ Padionov & Ecoobanus & Thile & 0000000000 & & aradonoverecodonus.com & \\
\hline AU MOTAMEDI & Pomericeau & RESEAROH ANO DEVELOPEMENT INTEAN & & & Ab:Motamedeponerieau. os & \\
\hline Amonn Tse & IBM & BiM marager & $+8522825-8616$ & & alvyntsegenkititam.com & \\
\hline Amber LN Huying & CPG Facilites Management & Biм & & & 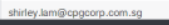 & \\
\hline
\end{tabular}

Fig. 3. Tab "Users"

The creation of an information model begins with filling in the fields "Floor", "Room", "Zone", where points of the height of the room, the purpose of the room/zone, area and other additional parameters are filled. Figure 4 shows a window of the EcoDomus software product.

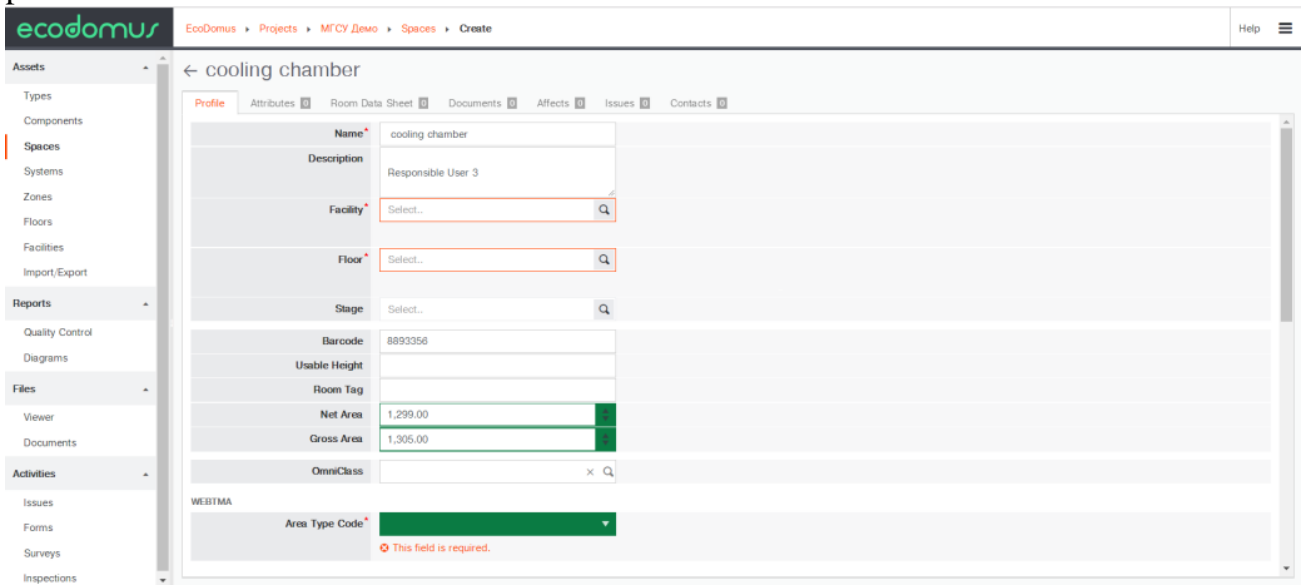

Fig. 4. Set "Floor", "Room", "Zone"

It is necessary to look at each system separately for management and control of the building, and the separate tab "Discipline", shown in figure 5 is provided on the panel of the program if it is required to build separately architectural model, or to look at a design of the building. 


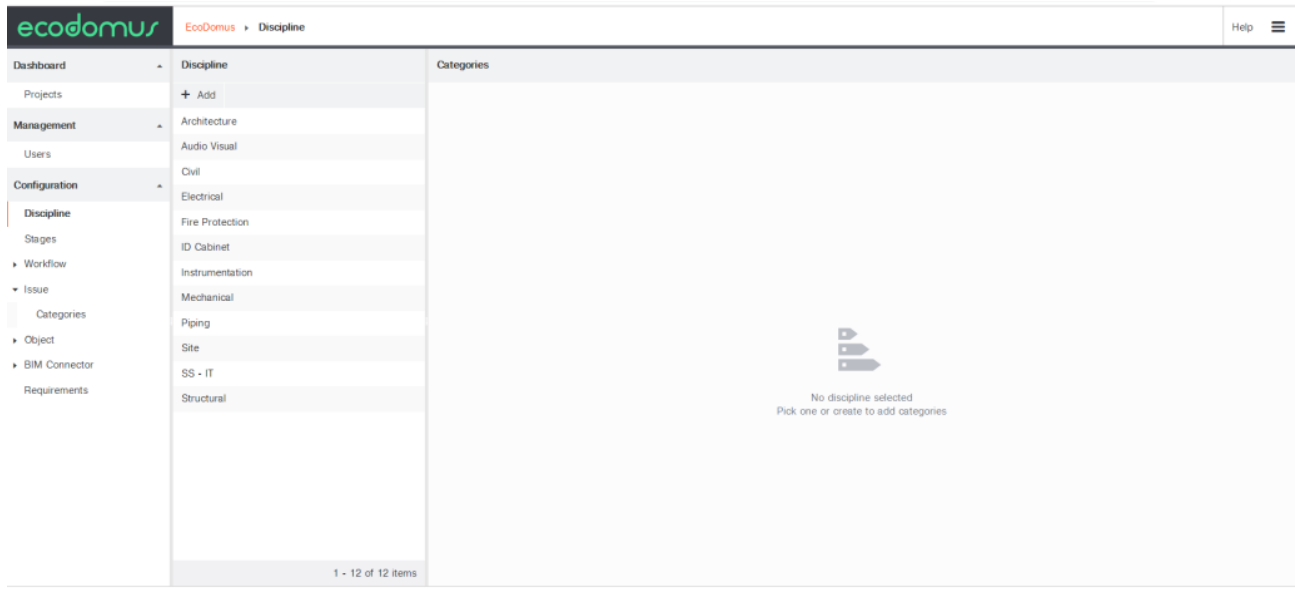

Fig. 5. Tab "Discipline"

Each "discipline" has its own staging for the best concept of completeness of a model. The design stage of the construction, the stage of completion of the construction in per cent and exploitation are pictured in figure 6 .

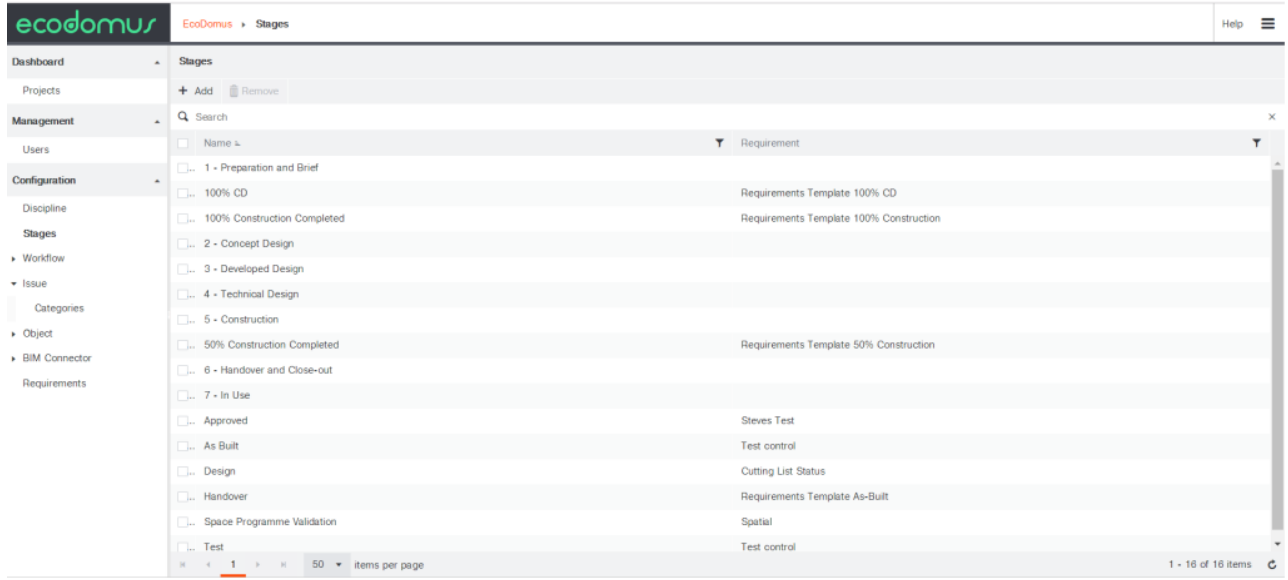

Fig. 6. Staging of the models

There is the tab "BIM Connector" for visual control of the models, it is a graphical execution of the model. In this case, the design of all models was performed with the help of Autodesk Revit 2018. Figures 7 and 8 show building information models with different types of visualization. 


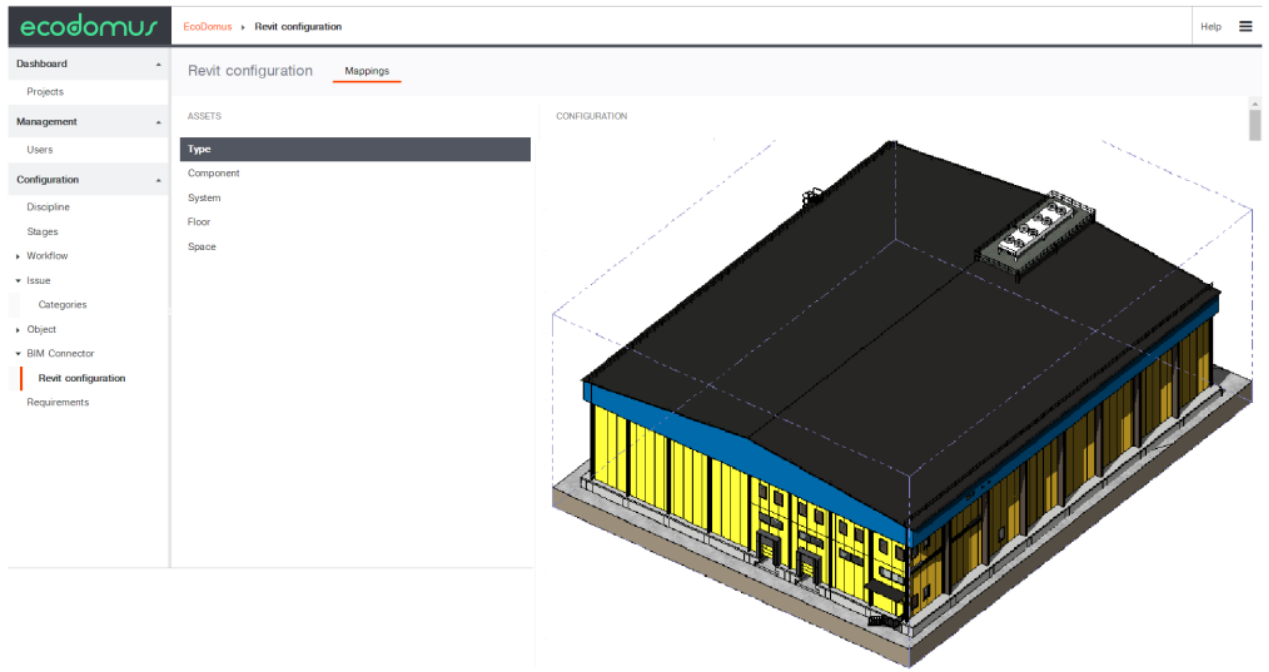

Fig. 7. Visual analysis of the building in EcoDomus

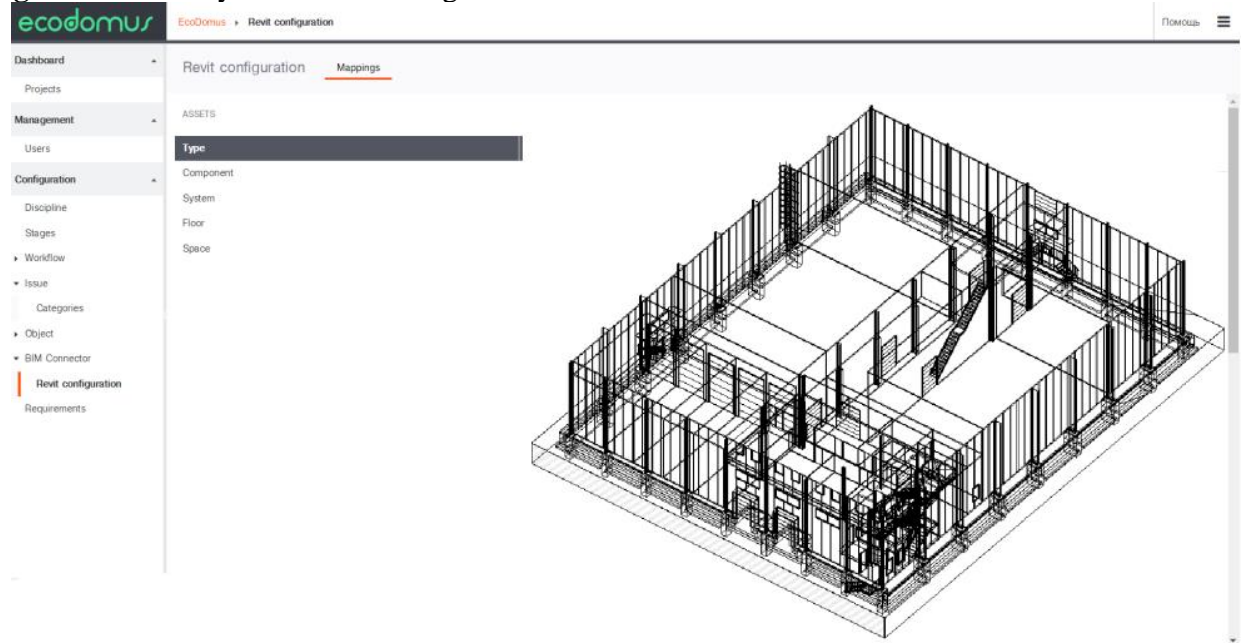

Fig. 8. Cross section of the building in wireframe view

Sometimes you just need to view all the elements of the system for maintenance or adjustment of the system during operation. You can easily look through any system with a view of each element, the information is reproduced in figures $9,10,11,12$. 


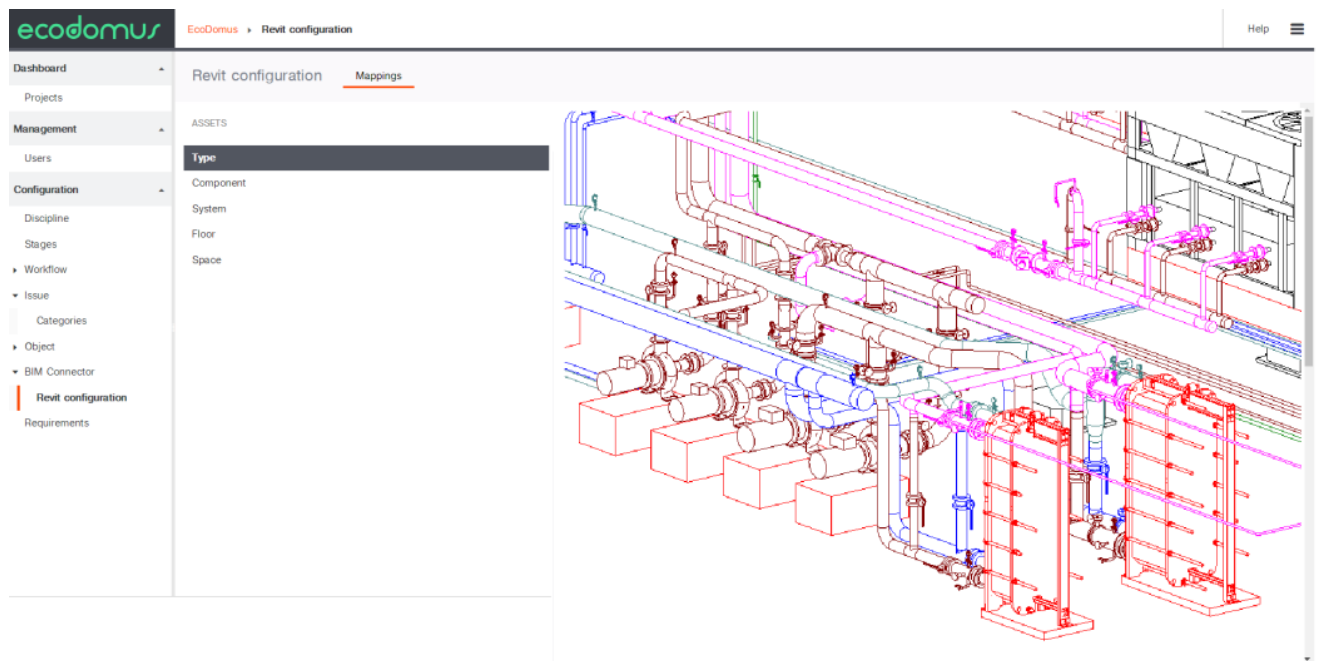

Fig. 9. Visual view of the refrigeration supply system with detailing of a unit in EcoDomus

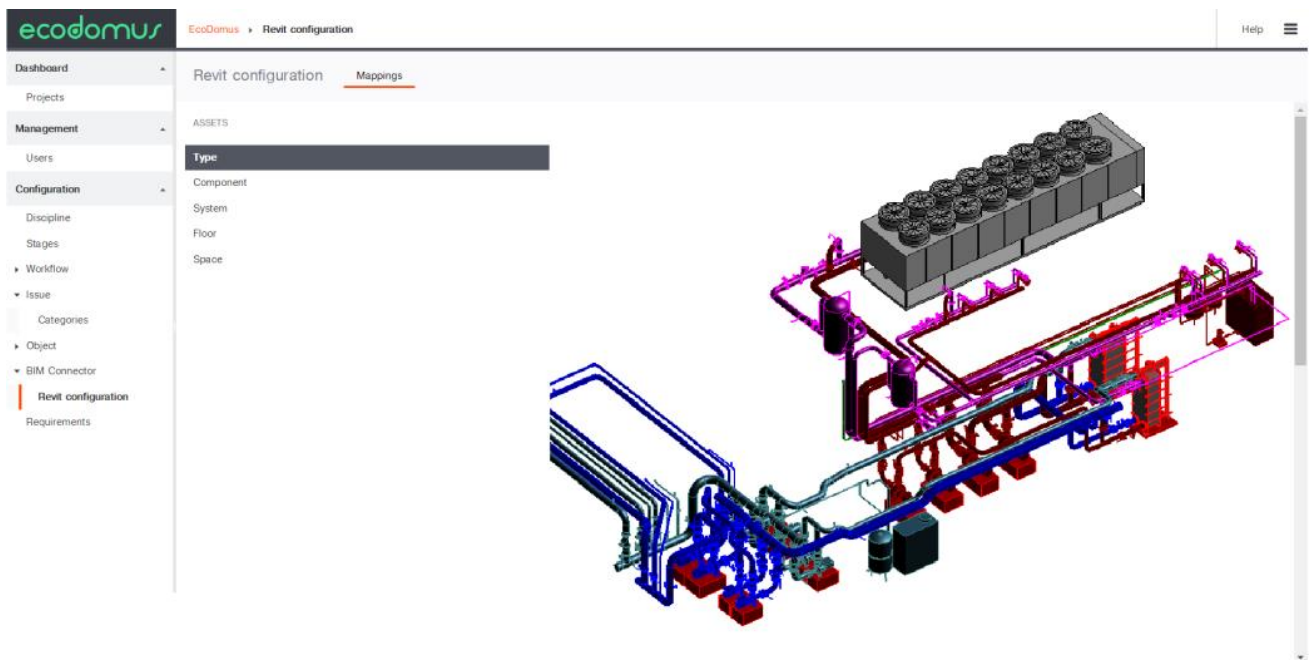

Fig. 10. Visual view of the refrigeration supply system with detailing of a unit in EcoDomus 


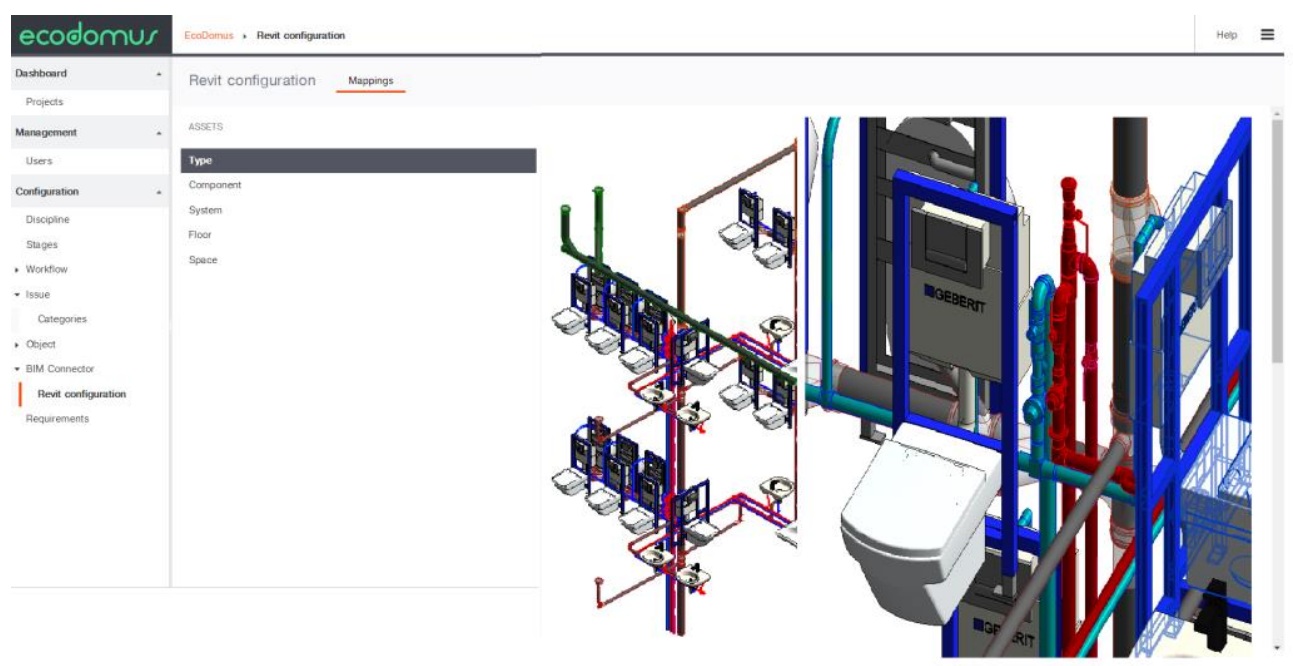

Fig. 11. Visual view of the water supply and sewerage system in EcoDomus in cooperation with the details of the recirculation unit

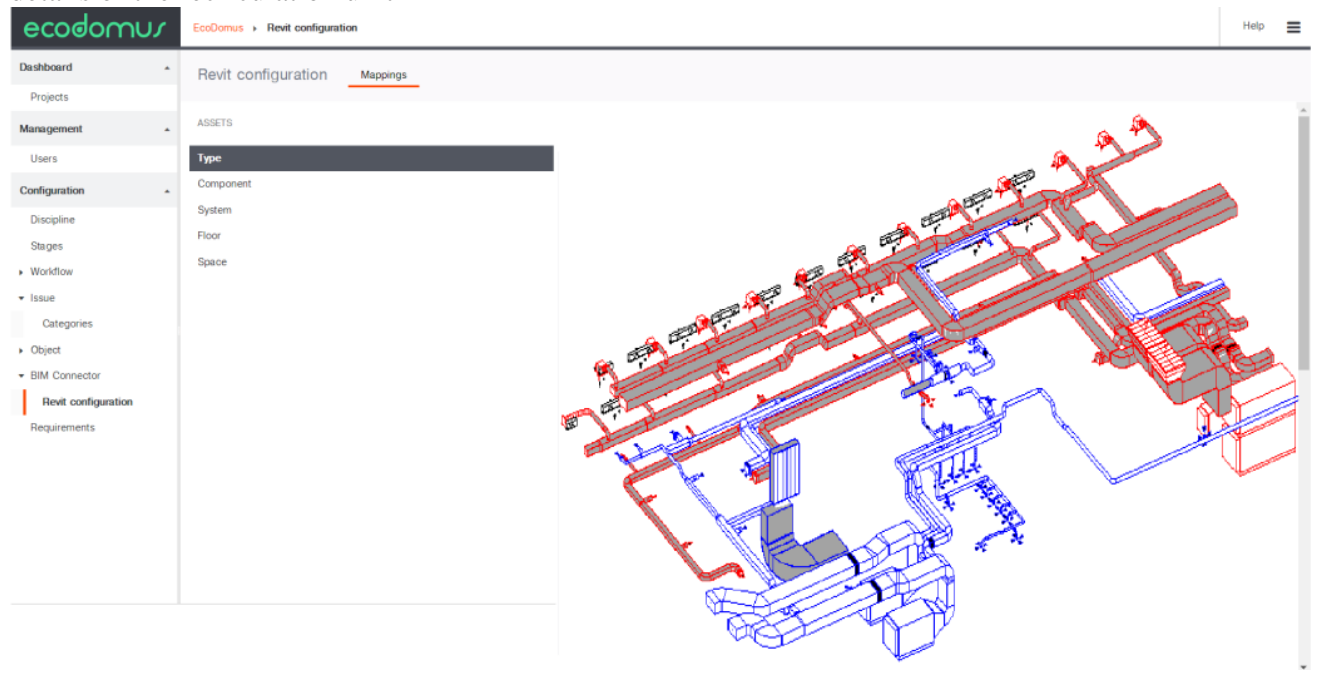

Fig. 12. Visual view of the ventilation system in EcoDomus

The question about the maintenance of the system elements is raised during the operation of the ventilation system, such as the replacing the filter. You can select the appropriate filter of a certain system and see the pressure drop in the program. That is exactly how the filter clogging is determined, the information is shown in figures 13 and 14. 


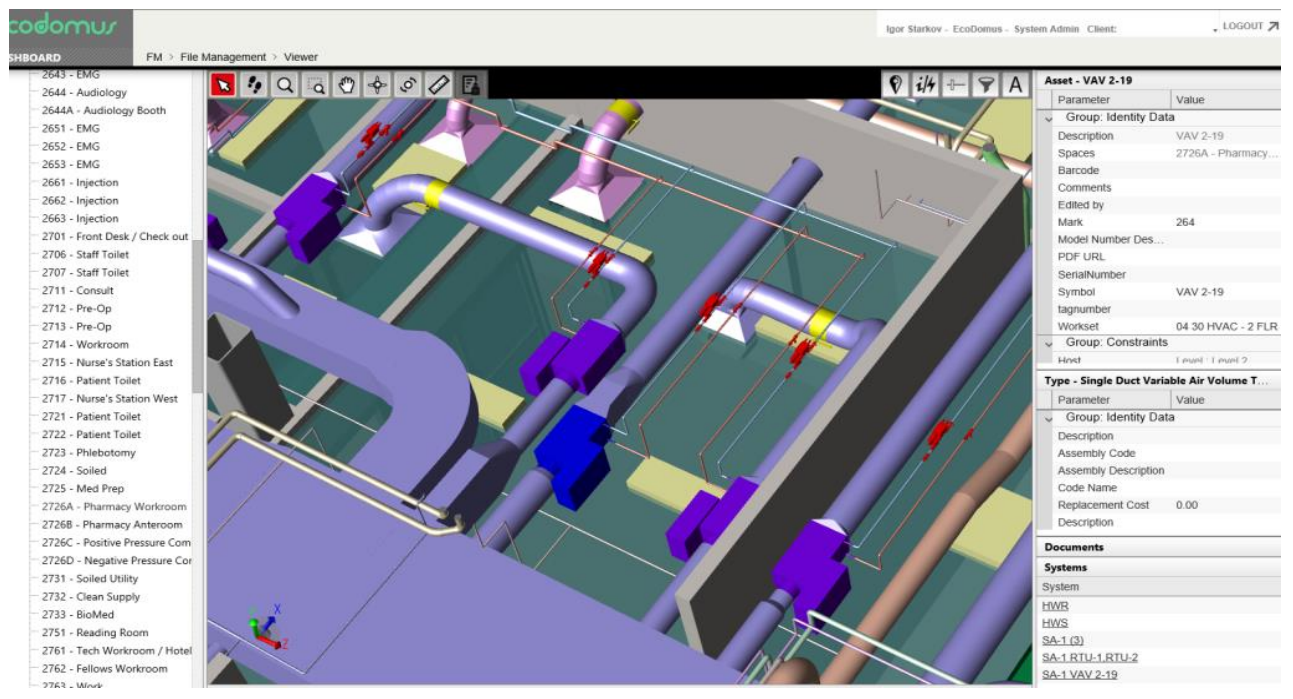

Fig. 13. View the ventilation model during the operation of the building

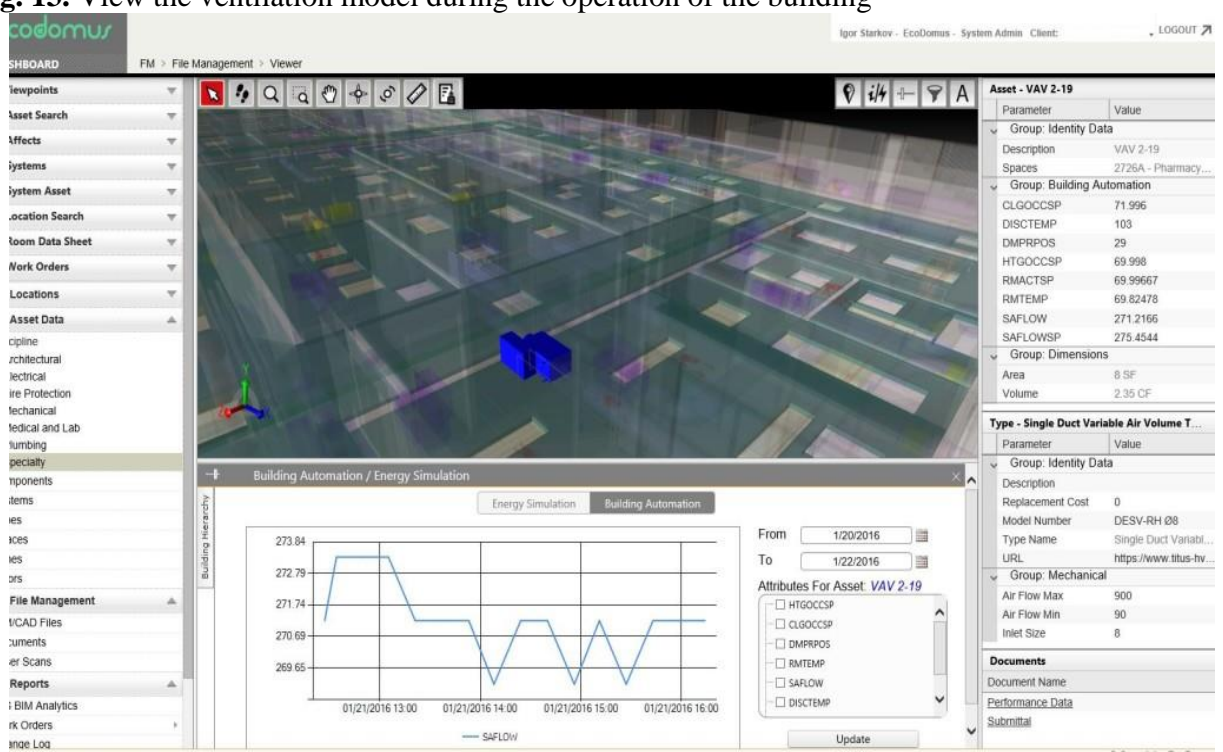

Fig. 14. Control of pressure drop on the filter in the supply ventilation system

In detecting defects in one of the elements of the ventilation system and identifying the impossibility of further use (replacement), it is very easy to check the technical data and maintenance regulations of this product. It is shown in figure 15 . 


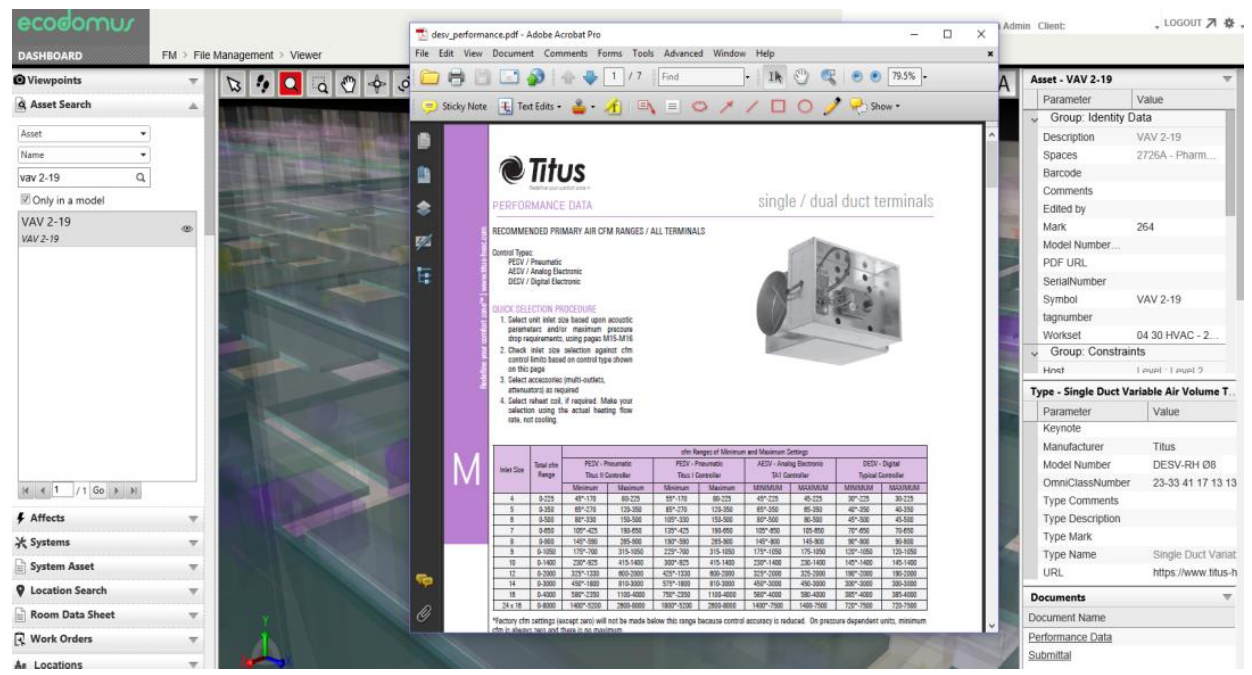

Fig. 15. View technical parameters of the fan for the subsequent replacement

It is necessary to have regulatory framework code of rules, regulations and other documentation during operation and maintenance which is presented in figure 16.,the document separation is performed by category in the software product.

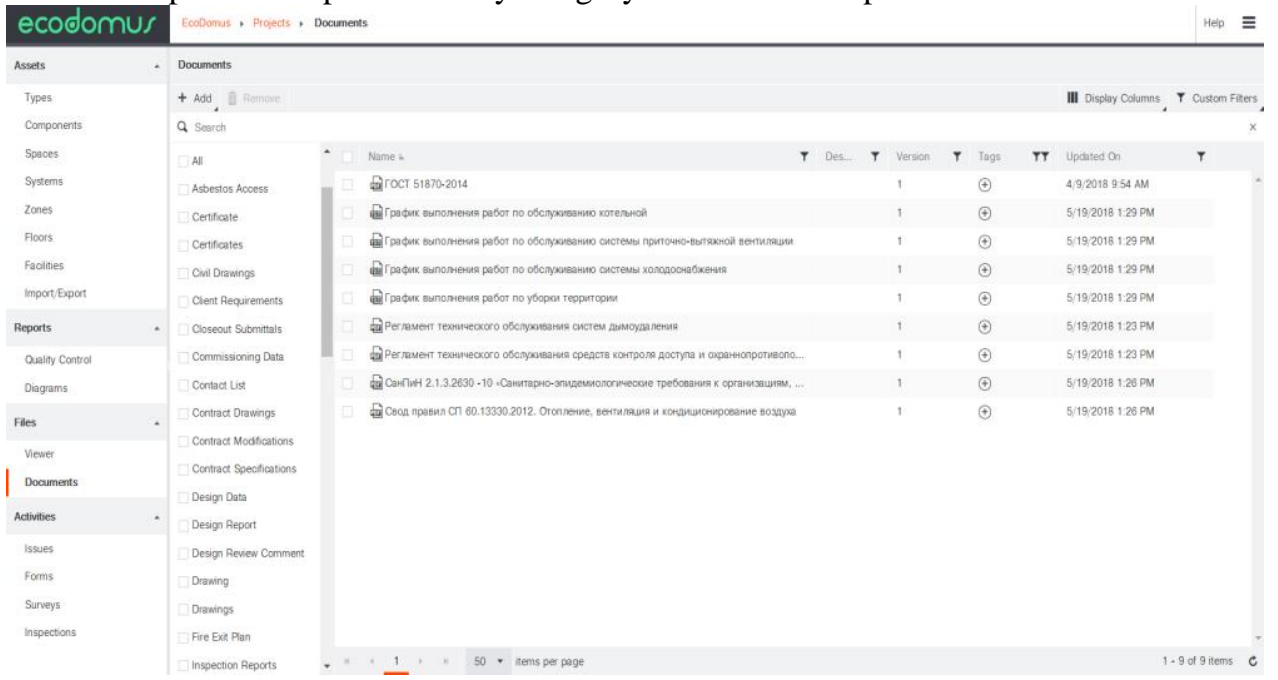

Fig. 16. Regulations

\section{Discussions and Conclusions}

The relevance of the consideration for the functioning of information management systems in organizations is determined by: achieving the maximum economic effect of their implementation; development (change) of computer networks of organizations and functional information management systems; changing the properties of hardware and software of computer networks; changing the structure of business processes of organizations [3]. 
Review of the experience of information systems demonstrates that the economic effect of their implementation depends on the completeness of the functionality of the software product. The reason for change of the quality in the management systems is to improve their software and hardware [2]. The structure of business processes is changing due to the expansion of the organization's ability to run business, it is connected with the emergence of new business areas or the development of existing business processes. The work of information management systems is a macrocycle which consists of such periods as preproject research, the implementation of the software product in the organization management system and the maintenance of the software product. In turn each of the periods includes several stages [6].

Considering of the functioning of information management systems, it is necessary to understand that such systems consist of several elements: platforms; configuration of a standard solution; configuration of a typical industry solution. It requires a clear understanding of what business operations will be automated and what effect will be expected from the implementation of the software product for automation of operational management and management accounting in the organization [8].

The reasons for the problematic issues are: lack of training of management staff with updated configuration of the information management system; savings on updating the hardware of the information (local) network of the organization.

Modernization of the information management system leads to economic costs, and the reason for these costs is the use of resources such as financial resources, human resources and time [4]. To reduce them, as the experience of the introduction of information management systems, companies try not to spend money on the modernization of equipment and training management to work with the upgraded information system. The implementation of these measures creates a situation where the costly modernization of the system, aimed at improving management efficiency and increasing the return on assets, leads to economic losses. That is why the opposite effect is achieved. The recommendation to remove such a situation is having a system modernization of the management system, which includes software and hardware upgrades and staff training [7].

This work was financially supported by Ministry of Education and Science of the Russian Federation (7.6932.2017/8.9). All tests were carried out using research equipment of The Head Regional Shared Research Facilities of the Moscow State University of Civil Engineering (RFMEFI59317X0006).

\section{References}

1. Volkov A., Kuzina, O. Complementary Assets in the Methodology of Implementation Unified Information Model of the City Environment Project Life Cycle. Procedia Engineering, 153, pp. 838-843. (2016)

2. Volkov A.A., Roytman, V.M., Shilova, L.A. Model of stability of life support systems in emergency situations. International Journal of Applied Engineering Research, 11 (3), pp. 1666-1669, (2016)

3. Volkov, A., Chulkov, V., Kazaryan, R., Fachratov, M., Kyzina, O. Possibility quantitative appraise components and guidance for constructional rearrangement of buildings attached to their confrontation // The 3rd Global Conference on Civil, Structural and Environmental Engineering - GCCSEE 2014,22.10.2014 / Advanced Materials Research (Trans Tech Publications, Switzerland). - Vols. 1065-1069, pp. 2585-2588. doi:10.4028/www.scientific.net/AMR.1065-1069.2585 / ISSN PRINT 1022-6680 ISSN CD 1022-6680 ISSN WEB 1662-8985 (2015)

4. Volkov, A., Chulkov, V., Korotkov, D. Life cycle of a building // The 3rd Global Conference on Civil, Structural and Environmental Engineering - GCCSEE 2014, 
22.10.2014 / Advanced Materials Research (Trans Tech Publications, Switzerland). Vols. 1065-1069 (2015). - pp. 2577-2580. doi:10.4028/www.scientific.net/AMR.10651069.2577 / ISSN PRINT 1022-6680 ISSN CD 1022-6680 ISSN WEB 1662-8985

5. Volkov A.A., Batov, E.I. Dynamic extension of Building Information Model for "smart" buildings (2015) Procedia Engineering, 111, pp. 849-852.

6. Volkov, A., Chulkov, V., Chulkov, G., Kazaryan, R., Kyzina, O. Qualities of documentation management chain (part 1) // The 3rd Global Conference on Civil, Structural and Environmental Engineering - GCCSEE 2014, 22.10.2014 / Advanced Materials Research (Trans Tech Publications, Switzerland). - Vols. 1065-1069 (2015). - pp. 2401-2404. doi:10.4028/www.scientific.net/AMR.1065-1069.2401 / ISSN PRINT 1022-6680 ISSN CD 1022- 6680 ISSN WEB 1662-8985

7. Galkina, E., Kuzina, $O$. Building information model verification at the lifecycle stage of construction // Volume 365, Issue 6, 2018, No 062031, 21st International Scientific Conference on Advanced in Civil Engineering: Construction - The Formation of Living Environment, FORM 2018.

8. Ginzburg, A., Kuzina, O., Ryzhkova, A. Unified resources marking system as a way to develop artificial intelligence in construction // Volume 365, Issue 6, 2018, No 062021, 21st International Scientific Conference on Advanced in Civil Engineering: Construction - The Formation of Living Environment, FORM 2018. 